\title{
Modern Systems Approach to Realize Higher Order Dynamic Circuits
}

\section{T. El-Ali*}

*Corresponding Author: College of Aeronautics, Engineering Program, Embry Riddle Aeronautical University-Worldwide, Daytona Beach, FL 32114, USA.

\begin{abstract}
Modern system approaches will be used to realize a 5th order dynamic differential equation as an analogue circuit using resistors, capacitors, and operational amplifiers. The resulting circuit will be tested using Matlab® and those results will be verified using Multisim. The state space approach will be used to convert the 5th order differential equation to five first order differential equations. Using the Multisim simulator, various input types were tested across the input terminals of the analog computer and the results were recorded.
\end{abstract}

Keywords: Analog Computer, State Space, Operational Amplifier, Resistor, Capacitor, Modern System Approach.

\section{INTRODUCTION}

The goal of this initiative is to build a $5^{\text {th }}$ order electronic circuit to solve and simulate a $5^{\text {th }}$ order differential equation with any input.

Consider the generic differential equation to be solved

$a \frac{d^{5}}{d t^{5}} y(t)+b \frac{d^{4}}{d t^{4}} y(t)+c \frac{d^{3}}{d t^{3}} y(t)+d \frac{d^{2}}{d t^{2}} y(t)+e \frac{d}{d t} y(t)$

$+f y(t)=g x(t)$

$\mathrm{x}(\mathrm{t})$ is the forcing function (the input to the system represented by this differential equation) and $\mathrm{y}(\mathrm{t})$ is the solution (the output of the same system). The variables a, b, c, d, e and f are some real constant numbers. [1]

In the last equation, (assuming zero initial conditions) let

$$
\left\{\begin{array}{l}
y_{1}(t)=y(t) \\
y_{2}(t)=\frac{d}{d t} y(t) \\
y_{3}(t)=\frac{d^{2}}{d t^{2}} y(t) \\
y_{4}(t)=\frac{d^{3}}{d t^{3}} y(t) \\
y_{5}(t)=\frac{d^{4}}{d t^{4}} y(t)
\end{array}\right.
$$

Thus we have the set of four first order differential equations 


$$
\left\{\begin{aligned}
& \frac{d}{d t} y_{1}(t)=y_{2}(t) \\
& \frac{d}{d t} y_{2}(t)=y_{3}(t) \\
& \frac{d}{d t} y_{3}(t)=y_{4}(t) \\
& \frac{d}{d t} y_{4}(t)=y_{5}(t) \\
& \frac{d}{d t} y_{5}(t)=-\frac{f}{a} y_{1}(t)-\frac{e}{a} y_{2}(t)-\frac{d}{a} y_{3}(t) \\
&-\frac{c}{a} y_{4}(t)-\frac{b}{a} y_{5}(t)+\frac{g}{a} x(t)
\end{aligned}\right.
$$

\section{Methodology}

Consider the Operational amplifier circuit shown in Figure 1. The input-output relationship is given a

$$
y(t)=-A \frac{1}{R C} \int x_{1}(t) d t-B \frac{1}{R C} \int x_{2}(t) d t
$$

In Figure 1, the output $y(t)$ is the integral of the input arriving at the negative terminal of the Operational Amplifier. Thus the negative of the derivative of $y(t)$ is located at the negative terminal of the Operational Amplifier. [2,3,4]

If we set $\mathrm{RC}=1$ in equation (3) we will have

$$
y(t)=-A \int x_{1}(t) d t-B \int x_{2}(t) d t
$$

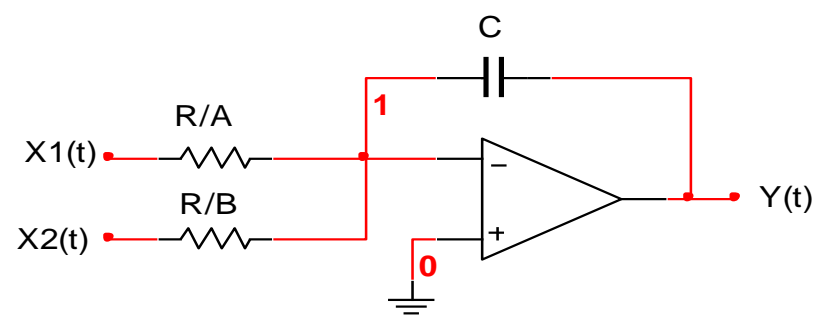

Fig1. Operational Amplifier Circuit

One final step before we attempt to implement Equation (4), the solution of a generic 1st order linear constant coefficient differential equation. Consider the circuit given in Figure 2. The input-output relationship is

$$
y(t)=-\frac{R_{f}}{R} x(t)
$$

You also can see that if $\mathrm{Rf}=\mathrm{R}$ then we have pure inversion (unity gain). The circuit containing an inverter and an integrator connected in series can solve the differential equation given in (6). Figure 3 is a typical example of such a circuit.

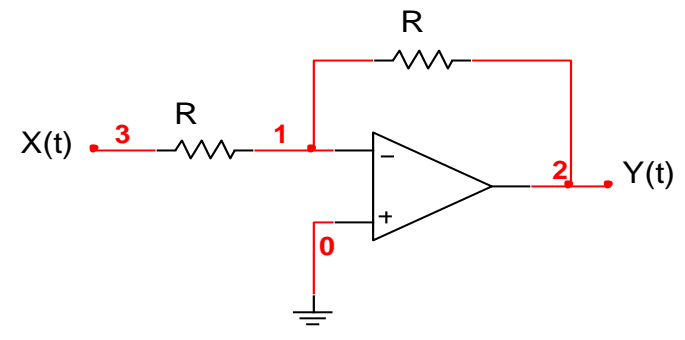

Fig2. Inverter 


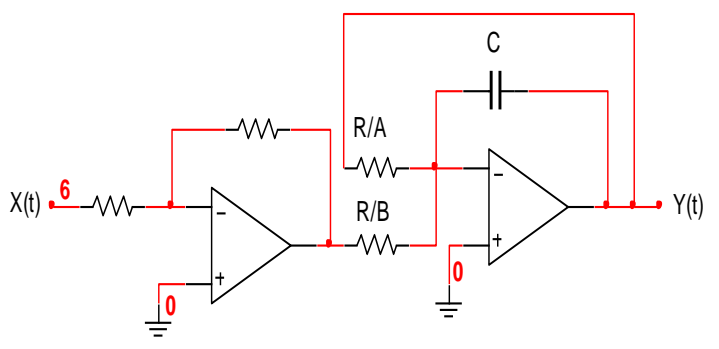

Fig3. A Circuit to Solve Equation 6

The circuit in Figure 3 would solve any first order differential equation of the form

$y^{\prime}(t)+A y(t)=B x(t)$

Knowing how to solve equation (6) is helpful in solving the set of the four coupled equations in (2) with y $(t)$ being the output in the fourth-order differential equation given in (1).

In building a circuit to solve the given differential equation in (1) we will use the set of equations in (2). We have tried step input, impulse input, and sinusoidal input. All worked nicely. Next we present the step response for different real coefficients and consider over damped, under damped, critically damped and oscillatory cases.

\subsection{Case 1}

For the over damped case we selected $\mathrm{a}=1, \mathrm{~b}=5, \mathrm{c}=8.75, \mathrm{~d}=6.25, \mathrm{e}=1.5, \mathrm{f}=0.0002$ and $\mathrm{g}=0.002$. The differential equation is then

$\frac{d^{5}}{d t^{5}} y(t)+5 \frac{d^{4}}{d t^{4}} y(t)+8.75 \frac{d^{3}}{d t^{3}} y(t)+6.25 \frac{d^{2}}{d t^{2}} y(t)+1.5 \frac{d}{d t} y(t)$

$+0.0002 f y(t)=0.0002 u(t)$

Where $u(t)$ is the step unit signal. The eigenvalues are then at

$-2.0000$

$-1.5000$

$-1.0000$

$-0.5000$

$-0.0001$

Using Matlab ${ }^{\circledR}$, the solution is plotted as seen in Figure 4.

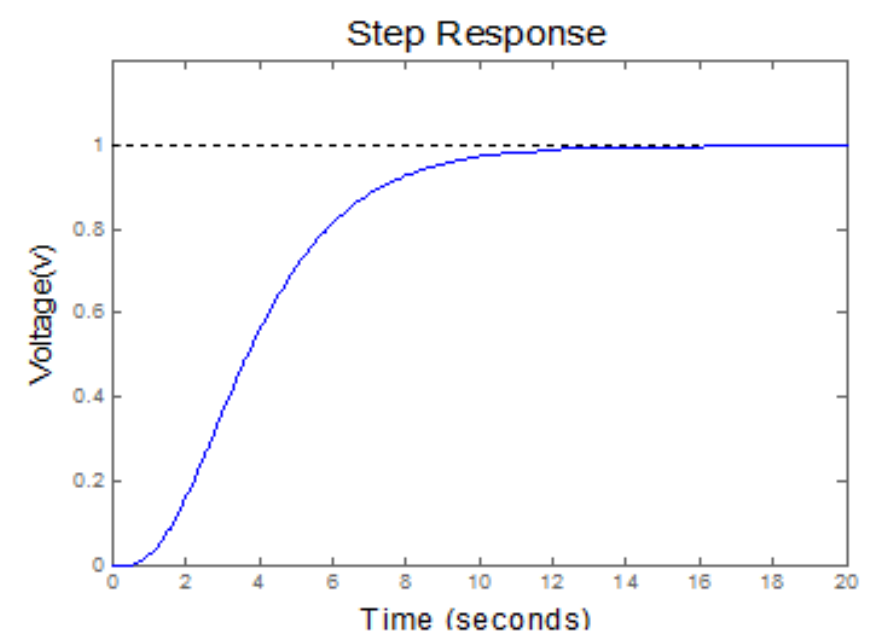

Fig4. Over Damped Case: Output from Matlab 
The circuit to solve the fifth-order differential equation with the given constant values and with the input $\mathrm{u}(\mathrm{t})$ is shown in Figure 5. For the input we used a pulse signal with pulse width of $20 \mathrm{sec}$ and period of $40 \mathrm{sec}$. To make $\mathrm{RC}=1$, we used $\mathrm{R}=1 \mathrm{k} \Omega$ and $\mathrm{C}=1 \mathrm{mF}$. We simulated for the first 20 second. The simulated output is shown in Figure 6.

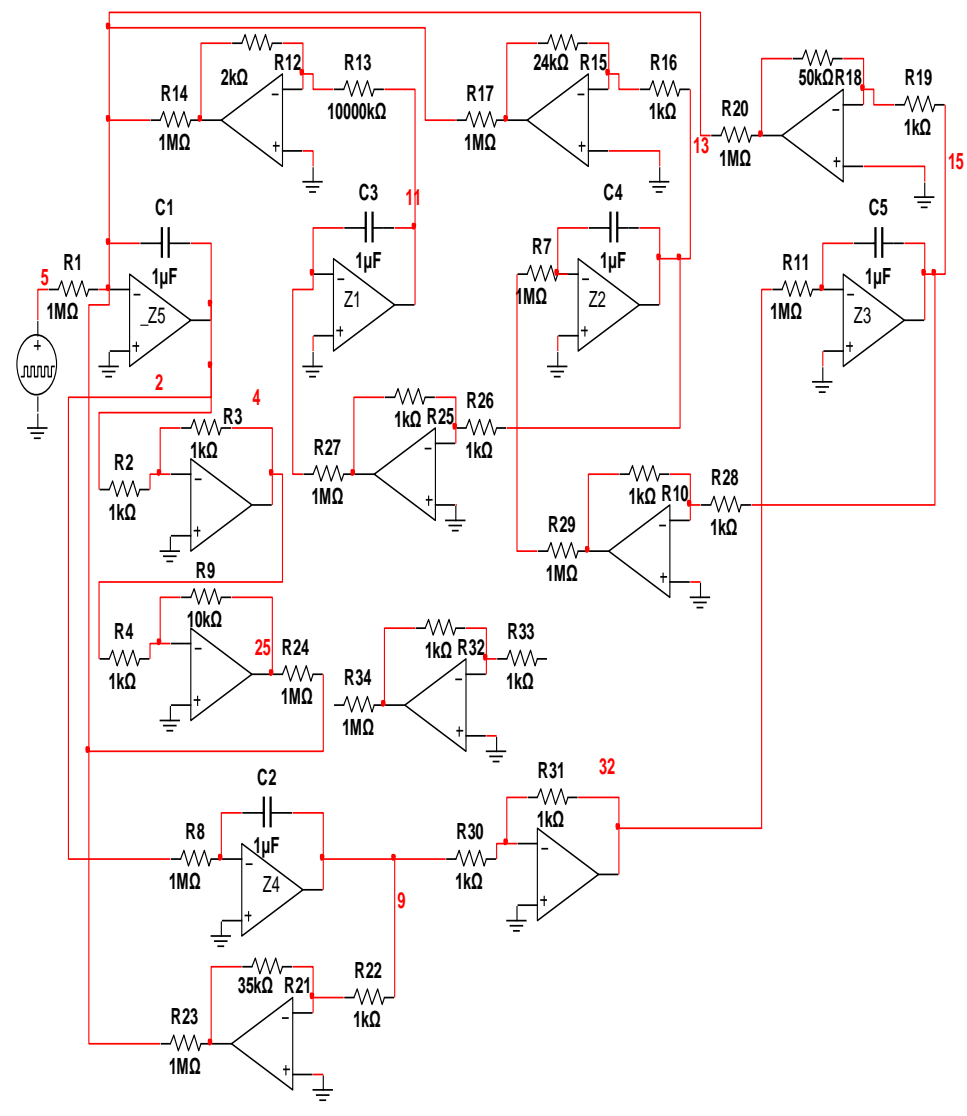

Fig5. Circuit to Solve the Differential Equation

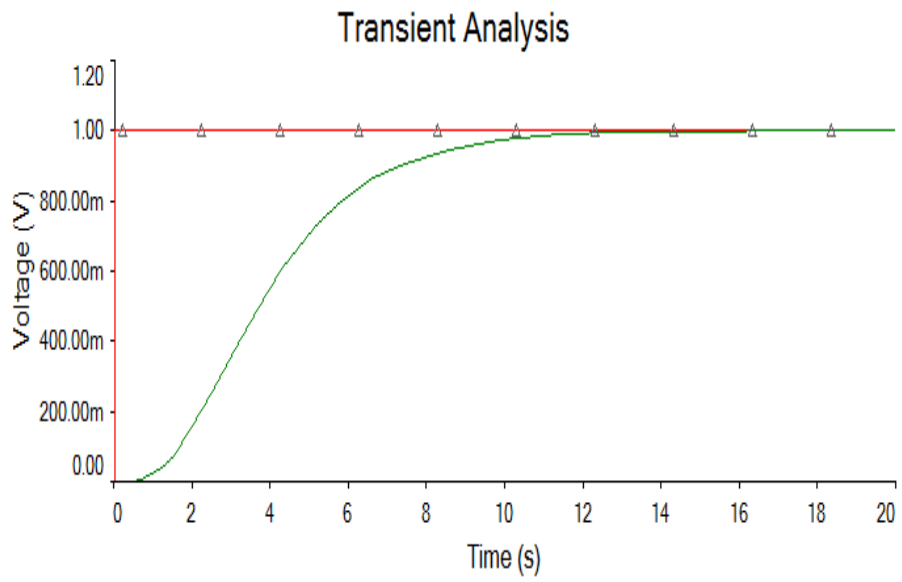

Fig6. Over Damped Case: from Circuit Simulation

\subsection{Case 2}

For the critically damped case we selected $a=1, b=6, c=13, d=12, e=4$ and $f=0.0004$. The differential equation is then

$$
\begin{aligned}
& \frac{d^{5}}{d t^{5}} y(t)+6 \frac{d^{4}}{d t^{4}} y(t)+13 \frac{d^{3}}{d t^{3}} y(t)+12 \frac{d^{2}}{d t^{2}} y(t)+4 \frac{d}{d t} y(t) \\
& +0.0004 f y(t)=0.0004 u(t)
\end{aligned}
$$


$\begin{array}{llllll}1.0000 & 6.0001 & 13.0006 & 12.0013 & 4.0012 & 0.0004\end{array}$

The eigenvalues are then at

$-1.0000$

$-1.0000$

$-2.0000$

$-2.0000$

$-0.0001$

Using Matlab, the solution is plotted as seen in Figure 7. For the circuit we used a pulse signal with pulse width of $20 \mathrm{sec}$ and period of $40 \mathrm{sec}$. To make $\mathrm{RC}=1$, we used $\mathrm{R}=1 \mathrm{k} \Omega$ and $\mathrm{C}=1 \mathrm{mF}$, the simulation done for the first 20 second and it is shown in Figure 8.

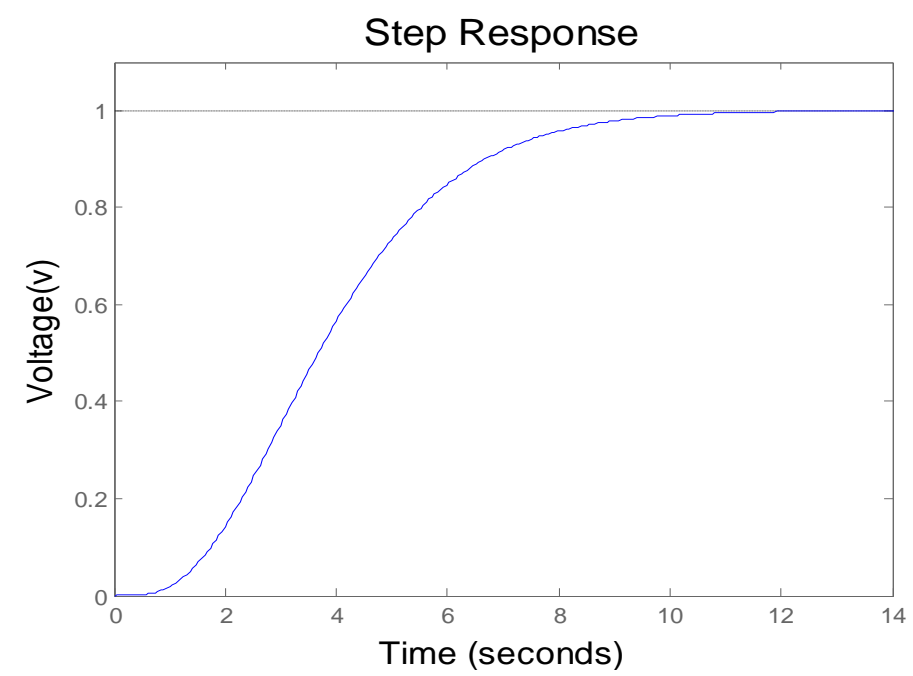

Fig7. Critically Damped Case: Output from Matlab

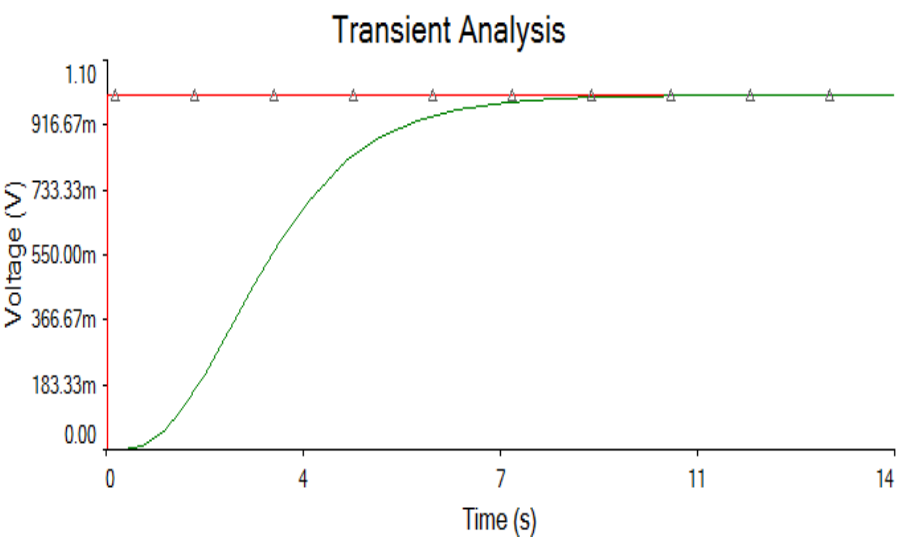

Fig8. Critically Damped Case: from Circuit Simulation

\subsection{Case 3}

For the oscillatory case we selected $a=1, b=3, c=3, d=3, e=2$ and $f=0.0001$. The differential equation is then

$$
\begin{aligned}
& 1.0000 \quad 3.0001 \quad 3.0003 \quad 3.0003 \quad 2.0003 \quad 0.0002 \\
& \frac{d^{5}}{d t^{5}} y(t)+3 \frac{d^{4}}{d t^{4}} y(t)+3 \frac{d^{3}}{d t^{3}} y(t)+3 \frac{d^{2}}{d t^{2}} y(t)+2 \frac{d}{d t} y(t) \\
& +0.0001 f y(t)=0.0001 u(t)
\end{aligned}
$$

The eigenvalues are then at 


\section{$-2.0000$ \\ $-0.0000+1.0000 \mathrm{i}$ \\ $-0.0000-1.0000 \mathrm{i}$ \\ $-1.0000$ \\ $-0.0001$}

Using Matlab, the solution is plotted as seen in Figure 9. For the circuit we used a pulse signal with pulse width of $20 \mathrm{sec}$ and period of $40 \mathrm{sec}$. To make $\mathrm{RC}=1$, we used $\mathrm{R}=1 \mathrm{k} \Omega$ and $\mathrm{C}=1 \mathrm{mF}$, the simulation is done for the first 20 second and it is shown in Figure 10.

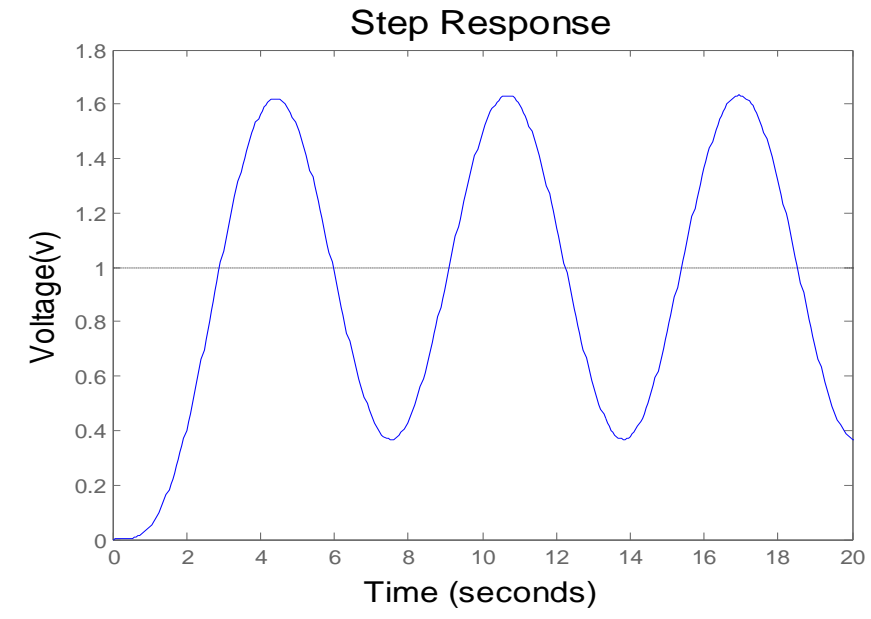

Fig9. Oscillatory Case: Output from Matlab

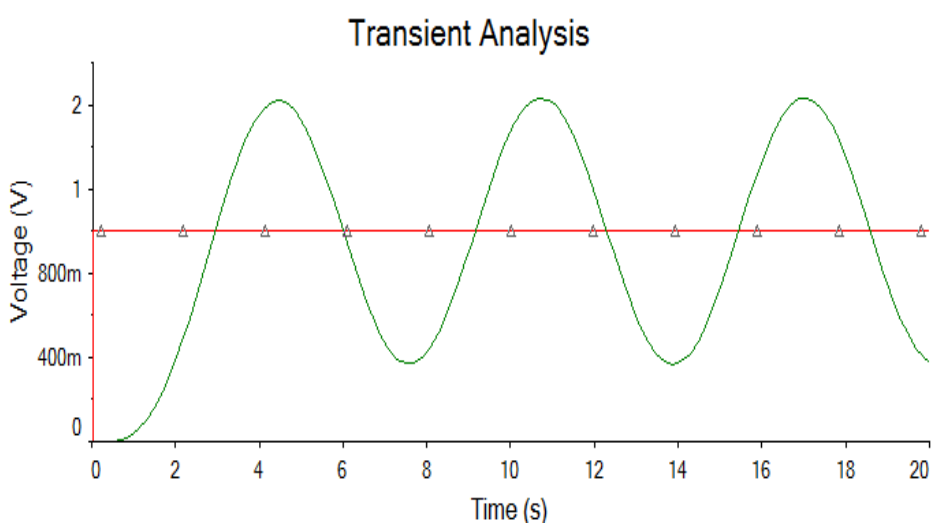

Fig10. Oscillatory Case: from Circuit Simulation

\subsection{Case 4}

For the under damped case we selected $a=1, b=4, c=6, d=9, e=5$ and $f=5$. The differential equation is then

$$
\begin{aligned}
& \frac{d^{5}}{d t^{5}} y(t)+4 \frac{d^{4}}{d t^{4}} y(t)+6 \frac{d^{3}}{d t^{3}} y(t)+9 \frac{d^{2}}{d t^{2}} y(t)+5 \frac{d}{d t} y(t) \\
& +0.0005 f y(t)=0.0005 u(t) \\
& \begin{array}{llllll}
1.0000 & 4.0000 & 6.0003 & 9.0008 & 5.0010 & 0.0005
\end{array}
\end{aligned}
$$

The eigenvalues are then at

$-2.7720$

$-0.2138+1.4860 \mathrm{i}$ 
$-0.2138-1.4860 \mathrm{i}$

$-0.8003$

$-0.0001$

Using Matlab, the solution is plotted as seen in Figure 11. For the circuit we used a pulse signal with pulse width of $25 \mathrm{sec}$ and period of $50 \mathrm{sec}$. To make $\mathrm{RC}=1$, we used $\mathrm{R}=1 \mathrm{k} \Omega$ and $\mathrm{C}=1 \mathrm{mF}$, the simulation is done for the first 25 second and it is shown in Figure 12.

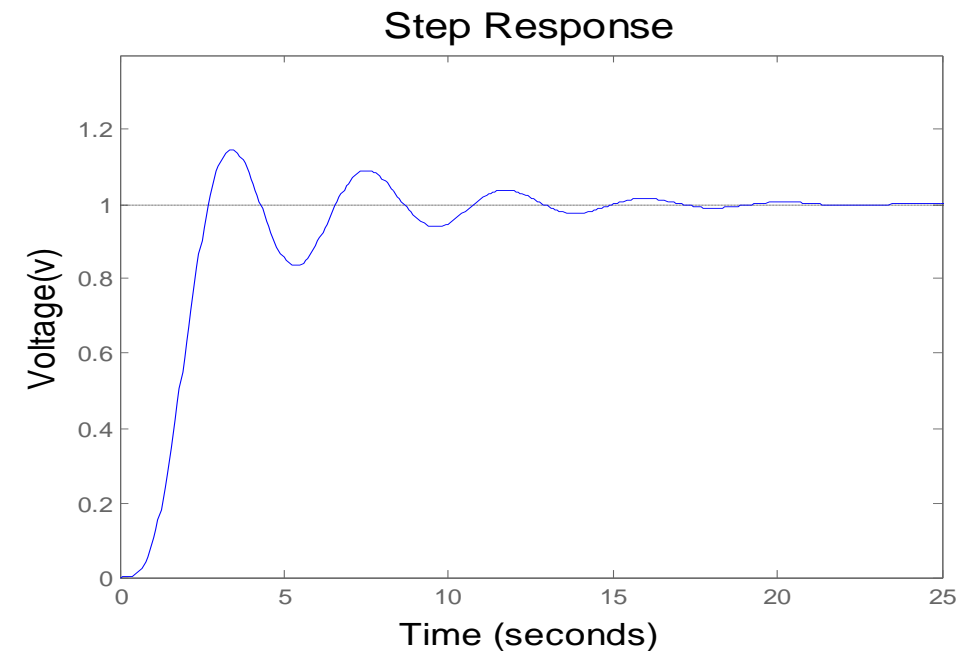

Fig11. Under damped Case: Output from Matlab

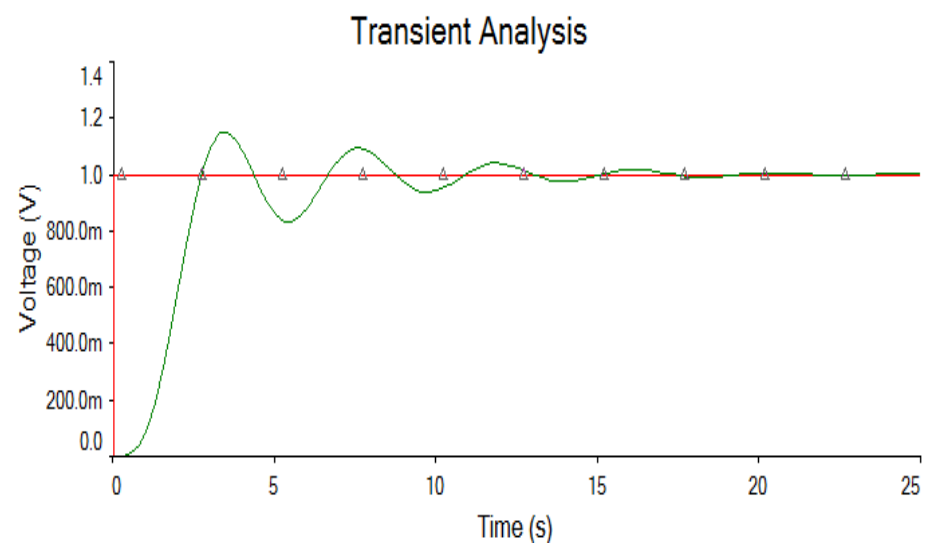

Fig12. Under damped Case: from Circuit Simulation

In the process of simulating the circuit we had to adjust the resistor values to accommodate the change in the coefficients.

The input $x(t)$ has to be adjusted too to accommodate the necessary time required to show enough time for the transients to settle.

\section{CONCLUSION}

It would be discovered by looking at the graphs and also by comparing these results with what was derived analytically that the circuits worked as desired. The differential equation was solved and its outputs were verified. The analog computer can be used to solve the two-point boundary-value problem for a fifth optimal control problem. It can also be applied to the study of micro-economic inventory system, for investigation a stock control system where the supply is discontinuous. [6] The analog computer also was found helpful in solving problems like simulation of a sampled data system, simulation of forecasting methods, locating a ware house or a distribution center, and controlling and resetting policies for process subject to trend. [7] In the future we will attempt to solve higher order differential equations. Practically, to solve any sixth order differential equation with any arbitrary coefficients requires a huge set of resistive values. However, since the constant values of a, b, c, d and e can be translated to ratios of resistor values that makes things easier. Issues related to amplifier saturation should also be studied. [5] 


\section{REFERENCES}

[1] H. Edward, Elementary Differential Equations, $4^{\text {th }}$ edition, Prentice Hall, 2000.

[2] R. Boylestad, Electronic Devices and Circuit Theory, $8^{\text {th }}$ edition, Prentice Hall, 2002.

[3] J. W. Nilson, Electric Circuits, $7^{\text {th }}$ edition, Prentice Hall, 2005.

[4] J. W. Nilson, Introduction to Pspice Manual using Orcad, $7^{\text {th }}$ edition, Prentice Hall, 2005.

[5] C. Chen, Analog \& Digital Control System Design, $1^{\text {st }}$ edition, Saunders, 1993.

[6] Vincent J. Darcy, An Application of an Analog Computer to solve the two-point boundary-value problem for a fourth order optimal control problem, Accession No. AD0639578, Jun 1966.

[7] S. Eilon and D.P. Deziel, The Use of an Analogue Computer in Some Operational Research, Vol.16, No.3, P.343, 345, Sep. 1965.

\section{AUTHOR'S BIOGRAPHY}

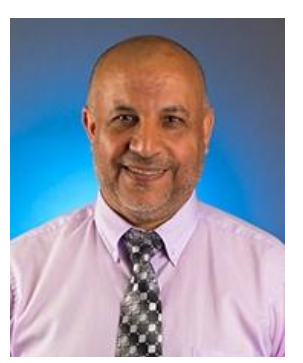

Dr. EIAli , has worked full-time at several academic institutions for more than 23 years in the areas of curriculum development, accreditation, teaching, research, etc. Dr. ElAli has discovered a new approach to dynamic system identification. Dr. ElAli has contributed many papers and conference presentations in the area of dynamic systems and signal processing. In his efforts to revolutionize the engineering education, Dr. ElAli has developed a new approach to Electrical Engineering education. This approach has led, among others, to the restructuring of one of the major courses in the engineering curriculum and thus to the restructuring of the textbooks used for the course. From this restructuring, two textbooks have emerged for the first time in the history of engineering education: "Continuous Signals and Systems with Matlab" and "Discrete Systems and Digital Signal Processing with Matlab."

Citation: T. El-Alil. (2018) "Modern Systems Approach to Realize Higher Order Dynamic Circuits", International Journal of Innovative Research in Electronics and Communications (IJIREC), 5(2), pp 1-8. DOI: http://dx.doi. org/10.20431/2349-4050.0502001

Copyright: () 2018 T. El-Ali, This is an open-access article distributed under the terms of the Creative Commons Attribution License, which permits unrestricted use, distribution, and reproduction in any medium, provided the original author and source are credited. 